\title{
Precedentes Judiciais: Conceito(s) e Características
}

\author{
Judicial Precedents: Concept(s) and Characteristics
}

Marcelo Luz Chaves

${ }^{1}$ Universidade Federal de Pernambuco - UFPE, Brasil

\section{Resumo}

O presente artigo tem por objetivo conceituar os "precedentes judiciais", bem como expor alguns de seus contornos, tais quais a possibilidade de serem fonte do direito (ainda que em ordenamentos de civil law), os diferentes graus de contribuição criativa que podem gerar ao ordenamento jurídico e os casos em que são considerados obrigatórios no direito brasileiro.

Palavras-chave: precedentes judiciais; precedentes obrigatórios; fontes do direito

\begin{abstract}
This paper aims to present the concept(s) of "judicial precedents", as well as to outline some of its characteristics, such as the possibility of being source of law (even in "civil law" sistems), the differents degrees of creative contributions that they can give to the law and the cases in wich they are consedered binding in brazilian law.
\end{abstract}

Keywords: judicial precedents; binding precedents; sources of law

\section{Introdução}

Os precedentes judiciais vêm aflorando como temática cada vez mais relevante no direito brasileiro. Embora não se possa desconsiderar a importância do tema à comunidade jurídica nacional já em tempos passados, uma vez que uma análise histórica nos mostra que o precedente "é uma realidade em sistemas jurídicos histórica e estruturalmente heterogêneos, e que apresenta características próprias em diferentes legislações", "fato é que, tradicionalmente, o instituto sempre gozou de mais prestígio nos sistemas jurídicos filiados à família do common law.

No sistema jurídico brasileiro, comumente apontado como pertencente à família do civil law, por muito tempo prevaleceu o discurso de que os precedentes não poderiam ter relevância normativa. A visão do instituto, contudo, tomou novos ares nas últimas décadas, estando numa crescente valorização: tivemos a autorização do julgamento monocrático de recurso manifestamente dissonante de ou consonante com "súmula ou com jurisprudência dominante do respectivo tribunal, do Supremo Tribunal Federal, ou de Tribunal Superior”"2 (art. 557, caput e $§ 1^{\circ}$, do CPC/1973, conforme alteração promovida

1 TUCCI, José Rogério Cruz e. Precedente judicial como fonte do direito. São Paulo: Revista dos Tribunais, 2004 , p. 304.

2 O conceito de precedente adotado no presente trabalho não abrange as súmulas, tampouco se confunde com a "jurisprudência dominante". Contudo, deve-se perceber que a instituição de mecanismos processuais que tomavam em 
pela reforma de 1998), a instituição da súmula vinculante (art. 130-A da CF/1988, introduzido pela EC n⿳0 45/2004), do julgamento liminar pela improcedência de causas repetitivas (art. 285-A do CPC/1973, introduzido em 2006), da eficácia vinculante da decisão que nega repercussão geral (art. 543-A, § 5 ${ }^{\circ}$, do CPC/1973, aditado em 2006), ${ }^{3}$ culminando, com a promulgação do Código de Processo Civil de 2015, na disciplina sistematizada pelo seu art. 927 dos chamados "precedentes obrigatórios".

Nesse contexto de solidificação da mudança de paradigma sobre os precedentes judiciais no sistema nacional, torna-se especialmente importante que a doutrina empreenda esforços para precisar os conceitos relacionados ao instituto, bem como delimitar suas características. O que são precedentes judiciais? O precedente pode ser considerado fonte do direito em um sistema de civil law? Por quê? De que maneira(s) os precedentes podem contribuir criativamente para o ordenamento jurídico? O que é um precedente obrigatório? Como se dá a vinculatividade a um precedente?

O presente artigo se propõe a responder essas perguntas, trazendo algumas noções-base para a adequada compreensão dos precedentes judiciais e seu papel no ordenamento jurídico brasileiro.

\section{Conceito(s) de Precedente Judicial}

A utilização de precedentes é uma forma de argumentação e de justificação ${ }^{4}$ utilizada em diversos âmbitos da vida humana. $\mathrm{O}$ apelo a um precedente nada mais é do que o uso da experiência para o convencimento de outrem ou a tomada de decisões: "o precedente é um evento passado (...) que serve como um guia para uma ação presente". ${ }^{5}$

Os precedentes não são, pois, um elemento único do sistemajurídico. Por vezes, os posicionamentos que um político toma são guiados por estratégias de campanhas que levaram à eleição de outros políticos no passado $;^{6}$ ou a decisão de um pai sobre dar de presente um celular à sua filha caçula de onze anos pode ser guiada pela idade que sua filha mais velha tinha ao receber seu primeiro telefone móvel. ${ }^{7}$

No que interessa ao direito, o termo "precedente" pode ter dois sentidos. ${ }^{8}$ Em sentido próprio, precedente judicial é o mesmo que decisão judicial precedente: é uma decisão tomada por um órgão judicial no passado, que - possivelmente - servirá como modelo para decisões posteriores. ${ }^{9}$ Nessa acepção, é entendido como precedente todo o ato decisório (relatório, fundamentação - inclusive os diversos votos, se houver - e dispositivo). Em outros termos, o precedente é um caso decidido no passado.

Ainda quanto ao sentido próprio, é de se perceber que só se costuma mencionar que um julgado "é um precedente" quando se está diante de um caso novo. Isso porque o precedente judicial tem forte aspecto relacional: ${ }^{10}$ a argumentação com precedentes só é relevante quando se está diante de casos

consideração as orientações jurisprudenciais foi um passo historicamente importante para o posterior reconhecimento da normatividade aos precedentes judiciais.

3 Parte das alterações legislativas aqui citadas foi compiladas por: MACÊDO, Lucas Buril de; PEREIRA, Mateus Costa; PEIXOTO, Ravi de Medeiros. Precedentes, cooperação e fundamentação: construção, imbrincação e releitura. Civil Procedure Review, v. 4, n. 3, p. 122-152, sep-dec., 2013, p. 125.

4 SCHAUER, Frederick. Precedent. Stanford Law Review, v. 39, n. 3, p. 571-605, fev./1987, p. 571.

$5 \quad$ DUXBURY, Neil. The nature and authority of precedent. Cambridge: Cambridge University Press, 2008, p. 1. No original: "A precedent is a past event (...) which serves as a guide for present action".

$6 \quad$ SCHAUER, Frederick. Thinking like a laywer: a new introduction to legal reasoning. Cambridge: Harvard University Press, 2009, p. 39.

7 DUXBURY, Neil. The nature and authority of precedente, cit., p. 2.

8 Adota-se a dualidade de acepções expostas, por exemplo, em: BANKOWSKI, Zenon; MACCORMICK, D. Neil; MARSHALL, Geoffrey. Precedent in the United Kingdom. In: MACCORMICK, D. Neil; SUMMERS, Robert S. (ed.). Interpreting precedents. Londres: Routledge, 2016, p. 323; MACÊDO, Lucas Buril de. Precedentes judiciais e o direito processual civil..., p. 77-81.

9 MACCORMICK, D. Neil; SUMMERS, Robert S. "Introduction”. In: Interpreting precedentes..., p. 1.

10 MACÊDO, Lucas Buril de. Precedentes judiciais e o direito processual civil. $3^{\mathrm{a}}$ ed. Salvador: JusPodivm, 2019 , p. 79 
análogos, de modo que um caso é "precedente" em relação àqueles que lhe sejam posteriores e com ele guardem similaridades. ${ }^{11}$

Em sentido impróprio, por sua vez, o signo "precedente" é empregado para designar a universalização das razões de decidir de um órgão judicial em um caso passado. Nesse sentido, "precedente" é utilizado em sinonímia à expressão ratio decidendi ou ao termo holding: é aquilo que, em certos casos, será a norma jurídica extraída de uma decisão judicial. É nessa acepção que comumente se sustenta que "um precedente deve ser aplicado", uma vez que não se aplica propriamente um caso, mas uma norma jurídica extraída do caso. ${ }^{12}$

Assim, os dois sentidos de "precedente" consubstanciam, de certo modo, uma relação de continente e conteúdo: ${ }^{13-14}$ (i) no sentido próprio, o precedente é o ato decisório observado enquanto possível instrumento de criação normativa, enquanto fonte do direito; (ii) no sentido impróprio, o precedente é o resultado desse ato criativo, são as razões de decidir passíveis de replicação e, em certos casos, é a norma jurídica que se extrai de uma decisão judicial (ratio decidendi).

$\mathrm{O}$ aspecto normativo do precedente judicial - seja enquanto fonte do direito, seja enquanto a própria norma jurídica - é, sem dúvidas, sua faceta mais relevante. Por esse motivo, alguns autores entendem que só se pode falar em precedente quando a decisão judicial tiver relevância institucional, inovando de alguma forma no ordenamento jurídico ${ }^{15}$ ou que os precedentes são sempre obrigatórios, ${ }^{16}$ conquanto as decisões cujas razões de decidir não forem vinculantes se tratam de jurisprudência. ${ }^{17}$ Não é o posicionamento adotado neste trabalho.

O conceito de precedente ora adotado é bastante amplo, abarcando, inclusive, os casos de decisões judiciais que não têm relevância normativa para o sistema. ${ }^{18}$ Ademais, entender que só se pode falar em precedente quando há vinculatividade quebraria com a tradicional dicotomia "precedente obrigatório x precedente persuasivo", que vem sendo utilizada há muito. Assim, parece-nos mais proveitoso assumir que a vinculatividade é um atributo incidental ao precedente, não lhe sendo característica definidora.

A relevância de um precedente, também é de se perceber, não está necessariamente ligada ao seu caráter normativo. Há situações tão peculiares que só foram enfrentadas em uma única oportunidade por um tribunal. Quando outro tribunal - não vinculado àquele - enfrenta pela primeira vez essa questão, decerto não estará vinculado às conclusões a que chegou a outra corte; entretanto, consoante o conceito ora adotado, o primeiro caso é precedente ao segundo, podendo, inclusive, ser relevante

11 "A precedent is simply any prior decision of any court that bears a legally significant analogy to the case now before a court" (BANKOWSKI, Zenon; MACCORMICK, D. Neil; MARSHALL, Geoffrey. Precedent in the United Kingdom, cit., p. 323). Ainda que o aspecto relacional seja marcante na visão comumente empregada ao precedente judicial, salutar é a observação de Lucas Buril (Precedentes judiciais e o direito processual civil, cit., p. 79), apoiado em Martin Orozco Munõz (La creación judicial del derecho y el precedente vinculante. Navarra: Arazandi-Thomson Reuthers, 2011, p. 32), de que "O fato de um precedente, entretanto, não possuir caso análogo não o exclui como fonte, apenas torna impossível sua aplicação”.

12 MACÊDO, Lucas Buril de. Precedentes judiciais e o direito processual civil, cit., p. 80.

13 A relação foi bem percebida por: MACÊDO, Lucas Buril de. Precedentes judiciais e o direito processual civil, cit., p. 81.

14 A afirmação, contudo, não deve ser compreendida como uma constatação de que a ratio decidendi "está" no precedente. Tal visão é tão reducionista quanto a de que uma norma "está" na lei.

15 "De modo que, se todo precedente ressai de uma decisão, nem toda decisão constitui precedente. (...) Nesta dimensão, é possível dizer que o precedente é a primeira decisão que, ao menos por maioria, decide a questão de direito ou é a decisão que, igualmente ao menos por maioria, definitivamente a delineia, deixando-a cristalina” (MARINONI, Luiz Guilherme. Precedentes obrigatórios [livro eletrônico]. $4^{\mathrm{a}}$ ed. São Paulo: Revista dos Tribunais, 2016, cap. III, t. 1.2.). "Dito de outra forma, apenas será precedente a decisão que resultar efeitos jurídicos normativos para os casos futuros” (ZANETI JR., Hermes. O valor vinculante dos precedentes. Salvador: JusPodivm, 2015, p. 329).

16 "os precedentes são oriundos de cortes institucionalmente encarregadas de dar a última palavra a respeito de como determinado desacordo interpretativo deve ser resolvido" e, assim, "o precedente tem sempre efeito vinculante, porque encarna a interpretação da Constituição ou da legislação federal em que se consubstancia a própria norma” (MITIDIERO, Daniel. Precedentes: da persuasão à vinculação. 2a ed. São Paulo: Revista dos Tribunais, 2017, p. 91 e p. 92).

18 São os precedentes declaratórios, como se verá no tópico 4. 
instrumento de persuasão aos julgadores deste, muito embora esse precedente não seja vinculante e se trate apenas de um caso isolado. ${ }^{19}$

\section{Precedente como Fonte do Direito}

É bastante difundida a visão de que os precedentes judiciais só têm relevância normativa nos sistemas de common law, por serem estes um judge-made law, enquanto os sistemas de civil law seriam incompatíveis com a vinculatividade dos precedentes, uma vez que nestes o juiz não deve criar direito, atividade restrita ao legislador. ${ }^{20-21}$ Esse discurso moldou a compreensão generalizada de que ambas as tradições jurídicas se situariam em extremos opostos, bem como de que os precedentes vinculantes seriam uma idiossincrasia própria do common law.

Essas premissas, contudo, não se sustentam. Se é certo que as tradições jurídicas guardam peculiaridades próprias, cada vez mais se percebe uma aproximação entre os sistemas jurídicos de troncos distintos, ${ }^{22}$ demandando a busca por soluções similares para problemas que lhes são comuns. Ademais, a noção de que o direito preexiste à decisão judicial não foi concepção restrita aos sistemas de civil law: a ultrapassada teoria declaratória da jurisdição, na verdade, ao passo em que sustentou a noção de ausência de vinculatividade aos precedentes no continente, teve papel importante para a construção de um sistema que respeita os precedentes no common law. ${ }^{23}$

Na Inglaterra, a visão do juiz como oráculo do direito (oracle of the law) advinha da compreensão de que suas decisões simplesmente declaravam o direito, que lhe preexistia. Por esse motivo, a partir do momento em que determinado direito fosse reconhecido por uma decisão judicial, os juízes posteriores deveriam observar o precedente, que era prova do próprio direito declarado. ${ }^{24} \mathrm{Na}$ França, de outro lado, a teoria declaratória da jurisdição levou a outro rumo. O sentimento de desconfiança da magistratura que marcou o período pós-Revolução Francesa levou à concepção da ideia do juiz inanimado (juge inanimé) ou do juiz boca da lei ( juge bouche de la loi). Em síntese, a centralidade da lei como única fonte normativa relevante foi tida como justificação para se retirar qualquer importância aos pronunciamentos judiciais sobre o significado da lei: só a lei vincula, não o que os precedentes dizem que a lei é. ${ }^{25}$

Apesar de ter sempre sido mais simpática à atribuição de importância aos precedentes judiciais, a doutrina do precedente vinculante (doctrine of binding precedent) só veio a se consolidar, nos termos em que hoje conhecidos, no século XIX. Alguns julgados ingleses são citados como sendo o anúncio da adoção dos precedentes vinculantes pela House of Lords, tais quais Beamisch v. Beamisch [1861] e Bradford v.

19 Acentuando a diferenciação quantitativa dos conceitos de precedente e jurisprudência: TARUFFO, Michele. Precedente e jurisprudência. Revista de Processo, v. 199, set. 2011; MACÊDO, Lucas Buril de. Precedentes judiciais e o direito processual civil, cit., p. 92-93.

20 Sobre a diferenciação entre as famílias jurídicas de common law e de civil law, conferir: DAVID, René. Os grandes sistemas do direito contemporâneo. Tradução de Hermínio A. Carvalho. $4^{a}$ ed. São Paulo: Martins Fontes, 2002.

21 "O sistema romanístico, assim, em oposição ao anglo-saxônico, caracteriza-se, em primeiro lugar, pela não vinculação dos juízes inferiores aos tribunais superiores em termos de decisões; segundo, cada juiz não se vincula às decisões dos demais juízes de mesma hierarquia, podendo decidir casos semelhantes de modo diferente; terceiro, o juiz e o tribunal não se vinculam sequer às próprias decisões, podendo mudar de orientação mesmo diante de casos semelhantes; em suma, vige o princípio (regra estrutural do sistema) da independência da magistratura judicial: o juiz deve julgar segundo a lei e conforme sua consciência. Por essas razões, a doutrina costuma negar à jurisprudência o caráter de fonte, ao contrário do que sucede com a teoria do precedente no mundo anglo-saxônico" (FERRAZ JR., Tércio Sampaio. Introdução ao estudo do direito: técnica, decisão, dominação. São Paulo: Atlas, 2018, p. 210-211).

22 Para uma ampla abordagem do tema, conferir: MARINONI, Luiz Guilherme. Aproximação crítica entre as jurisdições de civil law e de common law e a necessidade de respeito aos precedentes no Brasil. Revista da Faculdade de Direito - UFPR, Curitiba, n. 47, p. 29-64, 2008.

23 O ponto foi bem observado por: MARINONI, Luiz Guilherme. Aproximação crítica..., cit., p. 29-64, 2008; MITIDIERO, Daniel. Precedentes, cit., p. 25-26; MACÊDO, Lucas Buril de. Precedentes judiciais e o direito processual civil, cit., p. $166-167$.

24 MITIDIERO, Daniel. Precedentes, cit., p. 27-41;

$25 \quad$ Ibidem, p. 42-53. 
Pickles [1895], tendo a doutrina do stare decisis sido definitivamente reconhecida em 1898, no caso London Tramways Company v. London County Council. ${ }^{26}$

Em suma, o que se percebe é que a teoria do stare decisis ${ }^{27}$ não se confunde com o próprio conceito de common law, que inclusive lhe precede cronologicamente. O stare decisis foi apenas uma das características que historicamente se agregaram à tradição jurídica anglo-saxã. ${ }^{28}$ Essa constatação enfraquece ainda mais a ideia de que os precedentes vinculantes são elementos próprios dos sistemas de common law e necessariamente incompatíveis com o civil law. ${ }^{29}$

Pelo contrário: a atribuição de importância aos precedentes judiciais se mostra cada vez mais um rumo necessário aos sistemas romano-germânicos, principalmente a partir da superação da teoria declaratória da jurisdição. O mito de que não há criação do direito pelo juiz do civil law - ou em qualquer jurisdição - foi há muito derrubado, sendo um ponto comum na ciência jurídica moderna a constatação de que texto e norma não se confundem, bem como de que não há aplicação do direito que dispense a interpretação. ${ }^{30}$

Nesse passo, adotando-se a premissa básica de que - em alguma medida - o juiz cria direito, devese perceber que as cortes têm duas funções básicas: a resolução de disputas privadas e o enriquecimento do ordenamento jurídico. ${ }^{31} \mathrm{O}$ precedente, nesse contexto, passa a ser visto com especial relevância, como fonte do direito.

Diversas são as razões para se seguir precedentes. Sem a pretensão de se aprofundar nas justificativas para a adoção de um sistema precedentalista, cabe mencionar que o instituto tem a aptidão de fomentar a maior eficácia de valores como a segurança jurídica, a igualdade, a coerência da ordem jurídica, a duração razoável do processo e a eficiência do Judiciário. ${ }^{32}$

O respeito aos precedentes é uma medida imprescindível para qualquer ordem jurídica que se pretenda racional. Isso porque a atribuição de eficácia normativa às razões de decidir de um precedente

26 TUCCI, José Rogério Cruz e. Precedente judicial como fonte do direito. São Paulo: Revista dos Tribunais, 2004, p. 161.

27 “da expressão latina: stare decisis et non quieta movere = mantenha-se a decisão e não se moleste o que foi decidido" (TUCCI, José Rogério Cruz e. Precedente judicial como fonte do direito, cit., p. 160).

28 MARINONI, Luiz Guilherme. Aproximação crítica..., cit., p. 17-18.

29 Em interessante estudo histórico, Fredie Didier Jr. e Marcus Seixas Souza defendem que "o recrudescimento da importância do precedente judicial no Direito brasileiro não é um desvirtuamento, senão um aperfeiçoamento, da tradição jurídica com a qual sempre esteve associado o Direito brasileiro" (O respeito aos precedentes como diretriz histórica do direito brasileiro. Revista de Processo Comparado, ano 1, v. 2, jul.-dez./2015).

30 "O conceito de norma, desse modo, é colocado em plano pragmático (concreto) e não mais meramente semântico (abstrato) como entendem Kelsen e Alexy. A norma deixa de ser um mero esquema de interpretação de caráter semântico e passa a ser compreendida como a própria interpretação, que é inerente à atividade jurisdicional. A norma, assim, não possui significado ou normatividade em abstrato, mas apenas concretamente após a atividade interpretativa e construtiva" (ABBOUD, Georges; CAVALCANTI, Marcos de Araújo. Interpretação e aplicação dos provimentos vinculantes no novo código de processo civil a partir do paradigma do pós-positivismo. Revista de Processo, v. 245, p. 351 - 377, jul/2015, p. 3). Para uma apertada síntese do estado da questão da teoria da interpretação na doutrina brasileira: MITIDIERO, Daniel. Precedentes, cit., p. 65-68.

31 A constatação é feita por Melvin Eisenberg, quando às cortes de common law: "Like other complex institutions, common law courts serve several social functions, but two of these are paramount. The first concerns the resolution of private disputes. The second is the enrichment of the supply of legal rules to empower and govern private conduct" (EINSENBERG, Melvin A. The principles of legal reasoning in the common law. In: EDLIN, Douglas E. (ed.). Common law theory. Cambridge: Cambridge University Press, 2008, p. 81). A afirmação, contudo, vale igualmente para os demais sistemas, conforme percebe: MITIDIERO, Daniel. Precedentes, cit., p. 76.

32 MARINONI, Luiz Guilherme. Precedentes obrigatórios [livro eletrônico], cit., cap. II, item 2. O autor cita, ainda, outros razões para seguir precedentes: controle de poder do juiz (e de eventual imparcialidade), possibilidade de orientação jurídica (no sentido de possibilitar aos profissionais do direito segurança ao orientarem os leigos quanto ao posicionamento do Judiciário quanto a uma conduta), definição de expectativas, desestímulo à litigância, favorecimento de acordos, maior grau de aceitabilidade pelo jurisdicionado às decisões judiciais, racionalização do duplo grau de jurisdição e economia de despesas. 
depende da universalização de sua justificação: ${ }^{33}$ as razões utilizadas para o julgamento do caso de João devem, necessariamente, servir ao julgamento dos casos de Maria e José, que se encontram na mesma situação. Essa faceta racional da vinculatividade dos precedentes judiciais remete, inclusive, a um dos princípios de correção kantianos: "Dito de outro modo, o papel que a regra de comportar-se segundo os princípios que poderíamos querer como lei universal desempenha no âmbito da moralidade é o mesmo papel que o respeito ao precedente desempenha no âmbito jurídico". ${ }^{34}$

Do que se expôs, depreende-se que a tradicional negativa da força vinculante aos precedentes no civil lawé baseada em falsas premissas, e, especialmente, fecha os olhos para o necessário caráter criativo da atividade jurisdicional e para os benefícios da adoção de um sistema de precedentes vinculantes. O reconhecimento da vinculatividade dos precedentes parte da necessária compreensão de que a jurisdição cria direito para, a partir dessa premissa, estabelecer limites a essa criatividade. ${ }^{35}$ Em última instância, os precedentes obrigatórios são uma lembrança - e uma garantia - de que quem é dotado de autoridade criativa não é o magistrado, mas o Estado-juiz.

\section{Espécies de Precedente (quanto ao Grau de Contribuição Criativa)}

Estabelecido que o precedente judicial pode ser fonte do direito, cabe perceber que ele nem sempre o é, ${ }^{36}$ e, mesmo quando é, pode contribuir para o ordenamento jurídico em dimensões diferentes. Trata-se de classificar as espécies de precedente tomando como critério o grau de sua contribuição criativa.

Para tanto, adota-se a classificação proposta por Lucas Buril, que vislumbra a existência de precedentes (i) originários, (ii) determinantes e (iii) declaratórios. ${ }^{37}$

Situações há em que não existe tratamento legal sobre a matéria posta a julgamento, tornandose necessário ao Judiciário a construção da regra jurídica aplicável a partir dos princípios. ${ }^{38}$ De mesmo modo, às vezes a legislação disciplina determinada matéria, mas de modo incompatível com os princípios jurídicos pertinentes; faz-se necessário, então, o afastamento da regra legal pelo Judiciário e a construção da solução do caso a partir da operação com os princípios.

33 A universalização é, para Hermes Zaneti Jr., a principal razão para a adoção da vinculatividade dos precedentes, especialmente da vinculação horizontal (ZANETI JR., Hermes. O valor vinculante dos precedentes, cit., p. 354).

34 ABELLÁN, Marina Gascón. La técnica del precedente y la argumentación racional. Madrid: Tecnos, 1993 , p. 12 apud BUSTAMANTE, Thomas da Rosa de. Teoria do precedente judicial: a justificação e a aplicação de regras jurisprudenciais. São Paulo: Noeses, 2012, p. 268.

35 "Todos sabem que o juiz cria direito. É mais honesto intelectualmente reconhecê-lo de uma vez por todas e tentar estabelecer limites para esta 'criatividade' ou, em outras palavras, para o tal 'ativismo' judicial - que são conceitos muito próximos, cuja essência, no meu entender, como observei antes, é idêntica” (WAMBIER, Teresa Arruda Alvim. Precedentes e evolução do direito. In: WAMBIER, Teresa Arruda Alvim (coord.). Direito jurisprudencial. São Paulo: Revista dos Tribunais, 2012, p. 60). A mesma autora também acentua a vinculatividade dos precedentes como forma de redução da discrição do juiz em: WAMBIER, Teresa Arruda Alvim. A vinculatividade dos precedentes e o ativismo judicial - paradoxo apenas aparente. In: DIDIER JR., Fredie; CUNHA, Leonardo Carneiro da; ATAÍDE JR., Jaldemiro Rodrigues de; MACÊDO, Lucas Buril de (coords.). Precedentes. $2^{\mathrm{a}}$ ed. Salvador: JusPodivm, 2016. No mesmo sentido: MACÊDO, Lucas Buril de. Precedentes judiciais e o direito processual civil, cit., p. 166-175.

36 Ressalva-se, como já visto, a existência de autores que não classificam tais decisões judiciais como precedentes.

37 MACÊDO, Lucas Buril de. Precedentes judiciais e o direito processual civil, cit., p. 238-243.

38 Acentuando a necessidade da existência de uma regra intermediando o princípio e a decisão, Marcelo Neves anota: "Portanto, os princípios são razões mediatas de decisões de questões jurídicas, pois entre ele e esta sempre haverá uma regra, seja ela atribuível diretamente a texto produzido pelo processo legislativo (inclusive constituinte e reformador), seja ela atribuída (indiretamente) a um texto normativo mediante o órgão encarregado da concretização jurídica, isto é, mediante construção jurisprudencial” (NEVES, Marcelo. Entre Hidra e Hércules: princípios e regras constitucionais como diferença paradoxal do sistema jurídico. São Paulo: Martins Fontes, 2013, p. 84). Sua constatação é fundada no pensamento de Robert Alexy, que enxerga os princípios como "razões prima facie" e regras como "razões definitivas". Contudo, há certa dubiedade na obra do alemão, que pontualmente chega a afirmar que princípios também podem ser razões para decisões concretas. No ponto, conferir: ALEXY, Robert. Teoria dos direitos fundamentais. Tradução de Virgílio Afonso da Silva. $2^{\mathrm{a}}$ ed. São Paulo: Malheiros, 2015, p. 106-108. 
Em casos tais, a decisão judicial inova fortemente no ordenamento jurídico, implementando no sistema uma norma que não tinha prévio reconhecimento institucional. Em outros termos, a decisão cria uma norma que até então não existia. ${ }^{39}$ Essas situações cuidam de precedentes originários (ou criativos).

Quando outros casos similares chegarem novamente à apreciação judicial, o juiz não voltará a realizar aquela ponderação de princípios tomada no precedente originário; a regra jurídica estabelecida no caso paradigma (leading case) será suficiente para resolver o caso presente (instant case). O precedente originário passa a ser, então, o referencial normativo direto para a solução dos casos similares.

Em outras situações, as cortes se deparam com casos sobre os quais existe tratamento legal, mas há dúvidas quanto a algum aspecto da aplicação da norma. É que, em função da dupla indeterminação do direito, ${ }^{40}$ por vezes não se sabe se determinados fatos se enquadram ou não no suporte fático abstrato da norma; ou, ainda que se saiba qual a norma aplicável, suscita-se dúvidas sobre o seu consequente normativo. Em outras palavras, questiona-se: qual a norma aplicável? Quais consequências decorrem da aplicação dessa norma?

Ao julgar casos em que essas dúvidas são levantadas, o órgão judicial, por meio da interpretação dos dispositivos legais, necessariamente adscreverá novos elementos normativos ao sistema. Diante do dispositivo legal "se $x$, então $y$ ", a corte pode assentar que o fato $x$ ' enseja a aplicação da mesma norma, sanando a dúvida que antes pairava sobre o tema. De mesmo modo, pode definir que, em determinadas circunstâncias, deve ser conferida a consequência y' aos fatos $x$.

Com uma decisão dessa espécie, o Judiciário agrega maior grau de certeza aos contornos da norma, sem que, contudo, o precedente passe a ser o referencial normativo preponderante. A lei ainda é a fonte normativa principal a que o intérprete se reputa para a aplicação da norma; o precedente apenas fixa uma de suas possíveis interpretações. É o caso dos precedentes determinantes (ou especificadores).

Necessário que se perceba, ademais, que as leis não são os únicos textos normativos para os quais o aplicador do direito deve voltar suas atenções: também os precedentes necessitam de interpretação. Realmente, a decisão judicial precedente é texto, tal qual a lei, dotado de equivocidade, e a ratio decidendi que se extrai do julgado também é, em alguma medida, vaga. Por esse motivo, as decisões determinantes igualmente podem surgir a partir da interpretação de outros precedentes, agregando novos aspectos à ratio decidendi destes.

Ademais, mesmo reconhecida a indeterminação do direito, é certo que existem situações que não levantam dúvidas relevantes sobre a aplicação da norma. De fato, por vezes o texto legal é referencial normativo suficiente para a decisão, sem que a corte necessite agregar novos elementos à sua compreensão. De mesmo modo, há casos em que não se suscita maiores questionamentos quanto ao significado e extensão da ratio decidendi de um precedente, bem como de sua incidência em um novo caso que se coloque sob análise da corte.

Nessas situações, a decisão da corte será imprestável como fonte do direito, uma vez que não contribui criativamente para a determinação do ordenamento jurídico. Trata-se, pois, de precedentes declaratórios.

Cumpre esclarecer, por fim, que nem toda decisão que empregue interpretação literal será um precedente declaratório. A distinção entre os precedentes declaratórios e os determinantes reside precipuamente na existência de controvérsia relevante sobre o modo de ser da norma aplicada. Assim, se os operadores do direito não divergem sobre a interpretação de um dado dispositivo legal, a decisão

39 A criação, contudo, não é inteiramente livre, não é um ato puro de vontade: decorre das próprias normas jurídicas já existentes no sistema. "Ressalte-se, há novidade na norma geral construída. Isso não significa, todavia, que o juiz constrói a norma em um ato de vontade puro - é necessário que haja consistência sistêmica e congruência com as proposições sociais" (MACÊDO, Lucas Buril de. Precedentes judiciais e o direito processual civil, cit., p. 239).

$40 \quad$ "O direito é indeterminado basicamente por duas razões: os textos em que são vazados são equívocos e as normas são vagas. Essa é a razão pela qual se costuma afirmar a 'duplice indeterminatezza del diritto'. Os textos são equívocos porque ambíguos, complexos, implicativos, defectivos e por vezes se apresentam em termos exemplificativos ou taxativos. As normas são vagas porque não é possível antever exatamente quais são os fatos que recaem nos seus respectivos âmbitos de incidência” (MITIDIERO, Daniel. Precedentes, cit., p. 59). 
que aplica a norma dele decorrente será um precedente declaratório. De outro lado, se há controvérsia sobre a exegese do texto legal, a decisão que se vale da interpretação literal é precedente determinante, pois sana o debate, de modo que é considerada fonte do direito.

\section{Precedentes Obrigatórios}

Conforme se expôs, o precedente é apto a ser fonte do direito. Em outras palavras, normas jurídicas podem advir de precedentes judiciais. Quando essa for a hipótese, o órgão judicial que se deparar com um caso em que incida a norma de um precedente deverá aplicá-la. Não se trata de acatar as razões do precedente e, por isso, dar ao caso presente a mesma solução que foi dada no precedente; trata-se de aplicar a ratio decidendi do precedente porque consubstancia norma jurídica. ${ }^{41}$

É isso que significa a chamada vinculatividade dos precedentes. Sobre o tema, são esclarecedoras as considerações de Hermes Zaneti Jr.:

Vinculação formal significa que um julgamento que não respeita um precedente vinculante com relevância institucional, ou seja, com relevância constituída e regulada por normas jurídicas, não pode ser considerado juridicamente correto. Neste caso, a decisão será contrária ao direito (not lawful; illegitimo) e, portanto, poderá/ deverá ser objeto de reversão pelos meios de impugnação disponíveis no ordenamento jurídico. Portanto, vinculação formal será sinônimo de vinculação de iure e implicará o reconhecimento dos precedentes como fonte normativa primária formal, independentemente de seu conteúdo. ${ }^{2}$

Não são todos os precedentes, contudo, que são obrigatórios. Alguns não se prestam a ser fonte do direito, tais quais os precedentes declaratórios, como já visto. Outros, ainda que tragam algum grau de contribuição criativa, não terão suas razões de decidir entendidas como normas jurídicas. É o caso da decisão de um órgão fracionário de um Tribunal de Justiça, por exemplo, que dê determinada interpretação a um dispositivo da legislação federal: apesar das razões de decidir do precedente serem universalizáveis, ele não inserirá nova norma jurídica no ordenamento.

Assim, os precedentes podem ser classificados quanto à sua eficácia, desaguando em dicotomia bastante conhecida: serão obrigatórios ou persuasivos. ${ }^{43}$ Não obstante haja autorizada doutrina a defender outras classificações, com categorias intermediárias entre a total obrigatoriedade e o completo caráter persuasivo, ${ }^{44}$ entendemos ser mais adequada a classificação dicotômica. Isso porque o presente trabalho parte de uma abordagem dogmática do tema, olhando os precedentes sob a ótica do dever-ser, e não do ser. Não se analisará, aqui, o papel argumentativo dos precedentes, sua influência na prática

$41 \quad$ "The basic idea should now be clear. When courts are constrained by precedent, they are obliged to follow a precedent not only when they think it correct, but even when they think it incorrect. It is the precedent's source or status that gives it force, not the soundness of its reasoning nor the belief of the instant court that its outcome was correct" (SCHAUER, Frederick. Thinking like a lawyer, cit., p. 41).

42 ZANETI JR., Hermes. O valor vinculante dos precedentes, cit., p. 341-342.

43 MACÊDO, Lucas Buril de. Precedentes judiciais e o direito processual civil, cit., p. 87.

44 Hermes Zaneti Jr. propugna a classificação do que o presente estudo chama de "precedentes" em quatro categorias: jurisprudência persuasiva, precedentes normativos vinculantes, precedentes normativos formalmente vinculantes e precedentes normativos formalmente vinculantes fortes (ZANETI JR., Hermes. O valor vinculante dos precedentes, cit., p. 341346). José Rogério Cruz e Tucci, por sua vez, com o olhar direcionado ao sistema brasileiro de precedentes anterior ao CPC/2015, adota a tripartição entre precedentes com eficácia meramente persuasiva, precedentes com relativa eficácia vinculante e precedentes com eficácia vinculante (TUCCI, José Rogério Cruz e. Parâmetros de eficácia e critérios de interpretação do precedente judicial, cit., p. 111-122). Fora da doutrina nacional, o importante trabalho de direito comparado Interpreting Precedents leva em consideração a força argumentativa dos precedentes em cada ordenamento jurídico estudado, tomando como base a classificação dos precedentes em formalmente vinculantes (formal bindingness), não formalmente vinculantes, mas com força (not formally binding but having force), não formalmente vinculantes e sem força (not formally binding and not having force) e meramente ilustrativos (mere illustrativeness or other value). A classificação, utilizada em todo o estudo, é especialmente defendida em: PECZENIK, Aleksander. The binding force of precedent. In: MACCORMICK, D. Neil; SUMMERS, Robert S. (ed.). Interpreting precedents. Londres: Routledge, 2016. 
do discurso jurídico. ${ }^{45}$ Nesse sentido, cabe notar que ou um precedente é obrigatório ou não o é: tal qual o estado de "grávida", a obrigatoriedade é atributo não sujeito a gradações. ${ }^{46}$ Ou o precedente é obrigatório, gerando norma jurídica que deve ser seguida independentemente da qualidade de suas razões, ou não gera norma jurídica, e só interessará à justificação de decisões judiciais na medida em que convencer os órgãos julgadores.

Cabe a cada ordenamento jurídico estabelecer quais textos serão dotados de autoridade normativa. No que tange aos precedentes judiciais, atualmente, o principal referencial normativo sobre quais deles são fonte do direito é o art. 927 do Código de Processo Civil. ${ }^{47}$

O dispositivo, em seus incisos II e IV, corrobora o já tradicional reconhecimento de autoridade às súmulas no direito brasileiro, embora não se trate, propriamente, de uma espécie de precedente. ${ }^{48}$ É de se mencionar que a manutenção do emprego de súmulas em um sistema de precedentes é criticável, por serem institutos que partem de pressupostos distintos; ${ }^{49}$ contudo, uma análise mais a fundo das súmulas extrapola os limites do presente trabalho.

O inciso I, por sua vez, elenca as decisões em controle concentrado de constitucionalidade como precedentes obrigatórios. Para além da óbvia vinculação erga omnes decorrente da eficácia própria da decisão do Supremo Tribunal Federal nesses casos, as suas razões de decidir também constituem norma jurídica. ${ }^{50} \mathrm{O}$ julgamento contribui duplamente para o ordenamento jurídico: ${ }^{51}$ de um lado, define a (in)constitucionalidade de determinada norma (decisão); de outro, fornece as razões para que aquela norma seja (in)constitucional, o que será relevante para a definição da (in)constitucionalidade de outras normas similares (precedente). ${ }^{52}$

O inciso III trata das espécies de precedentes que formam o microssistema de formação concentrada de precedentes obrigatórios. ${ }^{53}$ Trata-se de procedimentos que devem ser tomados para o julgamento de casos com a específica finalidade de formar precedentes vinculantes, sujeitos a "normas que determinam a ampliação da cognição e da participação, qualificando o debate para a formação do precedente, a fundamentação reforçada e a ampla publicidade". ${ }^{4}$ Os precedentes que integram esse

$45 \quad$ "Sometimes cases from otherjurisdictions and from lower courts, learned treatises, law review articles, and nonlegal sources (like dictionaries, newspaper articles, and journals from nonlegal disciplines) are referred to as persuasive authorities, the idea being that a court will use them only if it is persuaded by the reasoning of the cited source. But if the court citing such material is genuinely persuaded, then it is misleading to think of the sources as authoritative at all, for persuasion and authority are fundamentally opposed notions. It is far better to describe these nonbinding sources as nonmandatory or, more felicitously, optional” (SCHAUER, Frederick. Thinking like a lawyer, cit., p. 69).

46 Apesar de não adotar a classificação dicotômica, o ponto foi percebido por: PECZENIK, Aleksander. The binding force of precedent, cit., p. 478.

47 Nesse sentido, o enunciado no 170 do Fórum Permanente de Processualistas Civis: "As decisões e precedentes previstos nos incisos do caput do art. 927 são vinculantes aos órgãos jurisdicionais a eles submetidos”.

48 Para a distinção entre súmulas e precedentes, ver: MACÊDO, Lucas Buril de. Precedentes judiciais e o direito processual civil, cit., p. 94-96.

49 Discorrendo sobre a súmula vinculante, Luiz Guilherme Marinoni tece considerações que servem às súmulas como um todo: "Na verdade, admitir súmula vinculante em relação a uma ratio delineada é supor que toda e qualquer ratio decidendi, para ter eficácia vinculante, depende da observância do procedimento instituído para a edição da 'súmula vinculante'. Portanto, é esquecer que há irreversível processo de redefinição da função do recurso extraordinário perante o Supremo Tribunal Federal" (Precedentes obrigatórios [livro eletrônico], cit., cap. IV, t. 1.4.).

$50 \quad$ Essa exegese foi incorporada no enunciado no 168 do Fórum Permanente de Processualistas Civis: "Os fundamentos determinantes do julgamento de ação de controle concentrado de constitucionalidade realizado pelo STF caracterizam a ratio decidendi do precedente e possuem efeito vinculante para todos os órgãos jurisdicionais”.

51 Explicitando o duplo discurso que pode ser tomado a partir da decisão judicial: MITIDIERO, Daniel. Fundamentação e precedente - dois discursos a partir da decisão judicial. Revista de Processo, v. 206, p. 61-78, abr./2012.

52 AVELINO, Murilo Teixeira. O que significa "decisão do Supremo Tribunal Federal em controle concentrado de constitucionalidade”?. In: CUNHA JÚNIOR, Dierle da; NOVELINO, Marcelo; MINAMI, Marcos Youji (coords.). Repercussões do novo CPC no controle concentrado de constitucionalidade. Salvador: Juspodivm, 2019, p. 343-363.

53 DIDIER JR., Fredie; CUNHA, Leonardo Carneiro da. Curso de direito processual civil. 15 ${ }^{\mathrm{a}}$ ed. Salvador: JusPodivm, 2018, v. 3, p. 689-692).

$54 \quad$ Ibidem, p. 691. 
microssistema são o incidente de assunção de competência - IAC, o incidente de resolução de casos repetitivos - IRDR, bem como os recursos extraordinário e especial repetitivos.

Por fim, o inciso $\mathrm{V}$ estabelece a vinculatividade dos posicionamentos do plenário ou do órgão especial de um tribunal a todos os juízos a ele vinculados. O que isso quer dizer é que os precedentes dos órgãos mais elevados de um tribunal são aptos a gerar norma jurídica, que será eficaz perante todos os juízos vinculados a esta corte (e, inclusive, perante os órgãos internos do mesmo tribunal). ${ }^{55}$

Essas são, em apertada síntese, as espécies de precedentes judiciais vinculantes no ordenamento jurídico brasileiro. ${ }^{56}$ Cabe perceber, contudo, que a atribuição de força normativa a um precedente judicial não significa que sua ratio decidendi será eficaz para todos os casos posteriores que surgirem: "não há precedente essencialmente vinculante. A obrigatoriedade sempre dependerá da perspectiva subjetiva, ou seja, do órgão do qual emanou o precedente e daquele que irá decidir". ${ }^{57}$ Daí se falar na vinculatividade horizontal e na vinculatividade vertical dos precedentes. ${ }^{58}$

Quanto à vinculatividade horizontal, os precedentes criam a obrigação de sua observância para o próprio órgão que o emanou. Com isso não se quer dizer que haja no sistema jurídico brasileiro - ou em qualquer outro, atualmente - "precedentes obrigatórios absolutos", que nunca poderiam ser contrariados pela própria corte ${ }^{59}$ Essa concepção foi inicialmente aceita na Inglaterra, sendo afirmado que a House of Lords, mais alta corte do país, ${ }^{60}$ estaria absolutamente vinculada aos seus próprios precedentes; contudo, em 1966, a corte proclamou o Practice Statement of Judicial Precedent, por meio do qual informou aos jurisdicionados que "a despeito de normalmente vinculante um precedente pronunciamento da House of Lords, os seus integrantes propõem modificar a praxe atual, podendo superar uma precedente decisão quando pareça oportuno". ${ }^{61}$

Assim, a vinculatividade horizontal deve ser entendida como a obrigatoriedade de respeito ao precedente pelo órgão que o emanou, a menos que o supere - o que só deve ser feito explicitamente e em situações específicas. ${ }^{62} \mathrm{O}$ respeito aos próprios precedentes é uma conduta necessária para que os tribunais assegurem a segurança jurídica, e vai ao encontro da exigência de que tenham uma jurisprudência uniforme, estável, íntegra e coerente, nos termos do art. 926 do CPC. ${ }^{63}$

A vinculatividade vertical, de outro lado, diz respeito à observância do precedente pelos órgãos judiciais vinculados àquele que o prolatou. Há, nessa perspectiva, uma obrigatoriedade de aplicação do precedente intimamente ligada à hierarquia da organização judiciária: dos precedentes obrigatórios de um tribunal local se extraem normas aplicáveis pelos juízes a ele vinculados; as rationes decidendi de precedentes obrigatórios dos tribunais superiores, por sua vez, vinculam os tribunais locais e os juízes componentes de seu ramo da estrutura judiciária.

55 Rebatendo a interpretação restritiva do dispositivo, pela qual apenas os órgãos de um mesmo tribunal estariam vinculados aos julgamentos de seu plenário ou corte especial: MACÊDO, Lucas Buril de. Precedentes judiciais e o direito processual civil, cit., p. 363-364. O mesmo autor também esclarece a melhor exegese do inciso V do art. 927 no que tange ao Superior Tribunal de Justiça, demonstrando que também as decisões de suas Seções Especializadas dão ensejo a precedentes obrigatórios (cit., p. 365-367).

56 Há quem entenda que o art. 927 estabelece um rol meramente exemplificativo de precedentes obrigatórios, como, por exemplo: MITIDIERO, Daniel. Precedentes, cit. p. 93.

57 MACÊDO, Lucas Buril de. Precedentes judiciais e o direito processual civil, cit., p. 90.

58 TUCCI, José Rogério Cruz e. Parâmetros de eficácia e critérios de interpretação do precedente judicial, cit., p. 104-

105 .

59 MACÊDO, Lucas Buril de. Precedentes judiciais e o direito processual civil, cit., p. 89.

60 Atualmente, a função é exercida pela Supreme Court of the United Kingdom, criada em 2009 para substituir o Appellate Committee of the House of Lords (https:/ / www.supremecourt.uk/about/the-supreme-court.html. Acesso em: 19 mai. 2021).

61 O trecho traduzido é citado por: TUCCI, José Rogério Cruz e. Precedente judicial como fonte do direito, cit., p. 159.

62 Sobre a superação do precedente, conferir: PEIXOTO, Ravi. Superação do precedente e segurança jurídica. $4^{\mathrm{a}}$ ed. Salvador: JusPodivm, 2019.

63 Conforme anotado no enunciado n⿳⺈ 453 do Fórum Permanente de Processualistas Civis: "A estabilidade a que se refere o caput do art. 926 consiste no dever de os tribunais observarem os próprios precedentes”. 
Importante perceber, ademais, que a relatividade das normas extraídas dos precedentes não o tornam "menos" fonte do direito. Não é porque a ratio de um precedente obrigatório do Tribunal de Justiça de Pernambuco não vincula um juiz de direito de São Paulo que ela perde seu caráter de norma: do mesmo modo que uma lei estadual só espraia eficácia no âmbito do respectivo Estado, a norma do precedente emanado por tribunal local só é eficaz no âmbito de sua competência. ${ }^{64}$

\section{Síntese Conclusiva}

À guisa de conclusão, propomos algumas constatações acerca dos precedentes judiciais, seus conceitos e características:

(i) Em sentido próprio, "precedente judicial" significa decisão judicial precedente: é um caso decidido no passado, que pode - ou não - ser relevante para a tomada de decisão no presente. Em sentido impróprio, "precedente" é entendido como a universalização das razões de decidir de um caso: é aquilo que, em certas hipóteses, será a norma jurídica extraída de uma decisão judicial (ratio decidendi ou holding);

(ii) O stare decisis não se confunde com o próprio conceito de common law, tampouco lhe é uma idiossincrasia, sendo apenas uma característica que se lhe agregou historicamente. De outro lado, a compreensão dos precedentes enquanto fonte do direito não é incompatível com os sistemas de civil law. Na verdade, a atribuição de eficácia normativa aos precedentes é providência útil aos sistemas jurídicos de ambas as famílias, especialmente quando considerada a superação da teoria declaratória da jurisdição;

(iii) Os precedentes contribuem criativamente para o ordenamento jurídico em diferentes medidas: (iii.a) quando a decisão constrói a regra jurídica aplicável a partir da operação com princípios, inova fortemente no sistema e, por isso, pode ser classificada como um precedente originário (ou criativo); (iii.b) quando já existe regra jurídica - decorrente da lei ou de precedente - que regule a matéria, mas há dúvidas quanto à extensão do suporte fático abstrato da norma ou quanto ao seu consequente normativo, a decisão que aplica a regra também agrega maior grau de certeza aos seus contornos, podendo ser entendida como um precedente determinante (ou especificador); (iii.c) quando um caso não suscitar dúvidas relevantes sobre a aplicação da norma - decorrente da lei ou de precedente -, a decisão que a aplica é imprestável como fonte do direito, sendo classificada como um precedente declaratório;

(iv) Os precedentes judiciais podem ser obrigatórios ou persuasivos. Serão obrigatórios quando o sistema jurídico outorgar o status de norma jurídica às suas rationes decidendi; por outro lado, serão persuasivos quando não forem considerados pelo sistema como fonte normativa;

(v) Quando um precedente for obrigatório, a vinculatividade de sua ratio decidendi prescinde da aceitação de suas razões. A ratio deve ser aplicada quando os fatos da causa se lhe subsumirem, inclusive quando o julgador do caso posterior não concordar com as razões do precedente. Em outras palavras, aplica-se a ratio simplesmente porque ela é norma jurídica;

(vi) O principal referencial normativo sobre os precedentes obrigatórios no direito brasileiro é o art. 927 do CPC, que estabelece algumas espécies de decisões judiciais das quais se extraem normas jurídicas. São precedentes obrigatórios: os julgamentos de ações de controle concentrado de constitucionalidade; os casos decididos em incidente de assunção de competência - IAC, em incidente de resolução de demandas repetitivas - IRDR e em recursos especial e extraordinário repetitivos; e os casos decididos pelos órgãos de cúpula de cada tribunal;

(vii) O âmbito de eficácia da norma do precedente depende do órgão que o prolatou: haverá vinculatividade horizontal para o próprio órgão, que deve respeitar sua ratio, a menos que expressa e excepcionalmente o supere; bem como haverá vinculatividade vertical para todos os juízos a ele vinculados dentro da hierarquia da organização judiciária.

64 MACÊDO, Lucas Buril de; ALMEIDA, Maria Eduarda. Os precedentes obrigatórios vinculam o tribunal arbitral?. Revista de Processo, v. 305, p. 377-399, jul./2020. 


\section{Referências}

ABBOUD, Georges; CAVALCANTI, Marcos de Araújo. Interpretação e aplicação dos provimentos vinculantes do novo código de processo civil a partir do paradigma do pós-positivismo. Revista de Processo, v. 245, p. 351 - 377, jul/2015.

ALEXY, Robert. Teoria dos direitos fundamentais. Tradução de Virgílio Afonso da Silva. 2ª ed. São Paulo: Malheiros, 2015

AVELINO, Murilo Teixeira. O que significa "decisão do Supremo Tribunal Federal em controle concentrado de constitucionalidade”?. In: CUNHA JÚNIOR, Dierle da; NOVELINO, Marcelo; MINAMI, Marcos Youji (coords.). Repercussões do novo CPC no controle concentrado de constitucionalidade. Salvador: Juspodivm, 2019.

BANKOWSKI, Zenon; MACCORMICK, D. Neil; MARSHALL, Geoffrey. Precedent in the United Kingdom. In: MACCORMICK, D. Neil; SUMMERS, Robert S. (ed.). Interpreting precedents. Londres: Routledge, 2016.

BUSTAMANTE, Thomas da Rosa de. Teoria do precedente judicial: a justificação e a aplicação de regras jurisprudenciais. São Paulo: Noeses, 2012.

DAVID, René. Os grandes sistemas do direito contemporâneo. Tradução de Hermínio A. Carvalho. $4^{a}$ ed. São Paulo: Martins Fontes, 2002.

DIDIER JR., Fredie; CUNHA, Leonardo Carneiro da. Curso de direito processual civil. $15^{\mathrm{a}}$ ed. Salvador: JusPodivm, 2018, v. 3.

DIDIER JR. Fredie; SOUZA, Marcos Seixas. O respeito aos precedentes como diretriz histórica do direito brasileiro. Revista de Processo Comparado, ano 1, v. 2, jul.-dez./2015.

DUXBURY, Neil. The nature and authority of precedent. Cambridge: Cambridge University Press, 2008.

EINSENBERG, Melvin A. The principles of legal reasoning in the common law. In: EDLIN, Douglas E. (ed.). Common law theory. Cambridge: Cambridge University Press, 2008.

FERRAZ JR., Tércio Sampaio. Introdução ao estudo do direito: técnica, decisão, dominação. São Paulo: Atlas, 2018.

MACCORMICK, D. Neil; SUMMERS, Robert S. Introduction. In: MACCORMICK, D. Neil; SUMMERS, Robert S. (ed.). Interpreting precedents. Londres: Routledge, 2016.

MACEDO, Lucas Buril de. Precedentes judiciais e o direito processual civil. $3^{\underline{a}}$ ed. Salvador: JusPodivm, 2019.

MACÊDO, Lucas Buril de; ALMEIDA, Maria Eduarda. Os precedentes obrigatórios vinculam o tribunal arbitral?. Revista de Processo, v. 305, p. 377-399, jul./2020.

MACEDO, Lucas Buril de; PEREIRA, Mateus Costa; PEIXOTO, Ravi de Medeiros. Precedentes, cooperação e fundamentação: construção, imbrincação e releitura. Civil Procedure Review, v. 4, n. 3, p. 122-152, sep.-dec./2013.

MARINONI, Luiz Guilherme. Aproximação crítica entre as jurisdições de civil law e de common law e a necessidade de respeito aos precedentes no Brasil. Revista da Faculdade de Direito - UFPR, Curitiba, n. 49, p. 11-58, 2009.

Precedentes obrigatórios [livro eletrônico]. $4^{\mathrm{a}}$ ed. São Paulo: Revista dos Tribunais, 2016.

MITIDIERO, Daniel. Fundamentação e precedente - dois discursos a partir da decisão judicial.

Revista de Processo, v. 206, p. 61-78, abr./2012.

Precedentes: da persuasão à vinculação. $2^{a}$ ed. São Paulo: Revista dos Tribunais, 2017. 
NEVES, Marcelo. Entre Hidra e Hércules: princípios e regras constitucionais como diferença paradoxal do sistema jurídico. São Paulo: Martins Fontes, 2013.

PECZENIK, Aleksander. The binding force of precedent. In: MACCORMICK, D. Neil; SUMMERS, Robert S. (ed.). Interpreting precedents. Londres: Routledge, 2016.

PEIXOTO, Ravi. Superação do precedente e segurança jurídica. 4⿳⺈冂a ed. Salvador: JusPodivm, 2019.

SCHAUER, Frederick. Precedent. Stanford Law Review, v. 39, n. 3, p. 571-605, fev./1987.

Thinking like a laywer: a new introduction to legal reasoning. Cambridge: Harvard University Press, 2009.

TARUFFO, Michele. Precedente e jurisprudência. Revista de Processo, v. 199, set. 2011.

TUCCI, José Rogério Cruz e. Parâmetros de eficácia e critérios de interpretação do precedente judicial. In: WAMBIER, Teresa Arruda Alvim (coord.). Direito jurisprudencial. São Paulo: Revista dos Tribunais, 2012.

Precedente judicial como fonte do direito. São Paulo: Revista dos Tribunais, 2004.

WAMBIER, Teresa Arruda Alvim. A vinculatividade dos precedentes e o ativismo judicial - paradoxo apenas aparente. In: DIDIER JR., Fredie; CUNHA, Leonardo Carneiro da; ATAÍDE JR., Jaldemiro Rodrigues de; MACÊDO, Lucas Buril de (coords.). Precedentes. $2^{\mathrm{a}}$ ed. Salvador: JusPodivm, 2016.

. Precedentes e evolução do direito. In: WAMBIER, Teresa Arruda Alvim (coord.). Direito jurisprudencial. São Paulo: Revista dos Tribunais, 2012.

ZANETI JR., Hermes. O valor vinculante dos precedentes. Salvador: JusPodivm, 2015. 